\title{
Management of a compound carpometacarpal fracture in a lesser adjutant stork (Leptoptilos javanicus): a case report
}

\begin{abstract}
An adult male lesser adjutant stork (Leptoptilos javanicus) of Nandankanan Zoological Park, Odisha, India was keeping its right wing flexed throughout the day with dullness and partial loss of appetite. On physical examination of the right wing, the sharp edge of bone was found protruding outside with breach of skin. Radiography of the wing confirmed compound carpometacarpal fracture at right wing. Keeping eye on its condition, external coaptation bandage technique was preferred over other methods of fracture reduction. The bird was confined to a small cage for 15 days to restrict its movement. The bird was administered with inj enrofloxacin and meloxicam for three days along with dressing of the site in three days interval. Radiographic images, after 15 days of bandage showed considerable callus formation at the fracture site. The bird was successfully recovered from fracture and released to its enclosure after one month and the bird was seen using its wings comfortably.
\end{abstract}

Volume 3 Issue 4 - 2018

\author{
Sarat Kumar Sahu,' Sidharth Mohapatra, ${ }^{2}$ \\ Rajesh Kumar Mohapatra,' Debabrat \\ Mohapatra' \\ 'Nandankanan Zoological Park, India \\ ${ }^{2}$ Orissa University of Agriculture and Technology, India
}

\begin{abstract}
Correspondence: Rajesh Kumar Mohapatra, Nandankanan Zoological Park, Odisha, India, Tel +9199 3756 3742,
\end{abstract} Email rajesh.wildlife@gmail.com

Received: August 01, 2018 | Published: August 20, 2018

Keywords: carpometacarpal, lesser adjutant stork, compound fracture, external coaptation, Nandankanan Zoological Park

\section{Introduction}

The lesser adjutant stork (Leptoptilos javanicus) is a large bird belonging to family Ciconiidae and found in wetlands of Southeast Asia. The present communication reports successful management of a compound fracture in a lesser adjutant stork by external coaptation technique which is very simple and cost-effective way of managing metacarpal fractures. ${ }^{1}$ Though bone fractures are common in both wild as well as captive birds, reports on the management of fractures in large birds like lesser adjutant stork are scanty. Avian bones, including the ones of the limbs, are thin brittle and tend to break into fragments upon a variety of natural events like midair collisions, fights with other birds. ${ }^{2}$ Treating wild birds with fractures require the consideration of a number of factors like size of the bird, post-treatment rehabilitation, method of restraint and associated stress. Considering the above factors external coaptation technique was found suitable with minimal physical restraint for captive wild birds where flight and foraging in post-treatment rehabilitation are non-substantial.

\section{Case history and observation}

One rescued adult male lesser adjutant stork was received at Nandankanan Zoological Park, Odisha, India on 12.06.2011. The stork was housed in a caged enclosure of floor area $120 \mathrm{Sqm}$ and provided with small fish $200 \mathrm{~g}$ and two day old chicks daily as feed. On 10.03.2018, the said stork was observed with flexed right wing, dullness and anorexia. Upon physical examination of the right wing, the sharp edge of bone was found protruding outside breaching skin. Radiographic examination of the affected wing revealed compound fracture of right carpometacarpal bone at the mid shaft (Figure 1). The wound site was soiled and blood stained. The bird was weighed to be $5 \mathrm{Kg}$.

\section{Treatment and management}

Considering the site of fracture and captive nature of the bird, it was decided to go for an external coaptation technique for treatment. An applicator splint was prepared by using ten pieces of thin bamboo sticks measuring about $15 \mathrm{~cm}$ in length and adhering micro pore bandage to it. The area was cleaned, disinfected and the antibiotic powder was applied. Reduction of fracture fragments was carried out and maintained manually in the aligned position. Then it was padded with adequate cotton and the splint was applied over it with the help of micropore bandage. To prevent wing flapping and further tissue damage, wing wrap method of bandaging was done by bending carpo-metacarpus bone close to radius ulna. Application of cotton gauge bandage over the splint in a figure ' 8 ' pattern involving carpi cranially and elbow caudally (Figure 2). The other wing is left free for balancing.

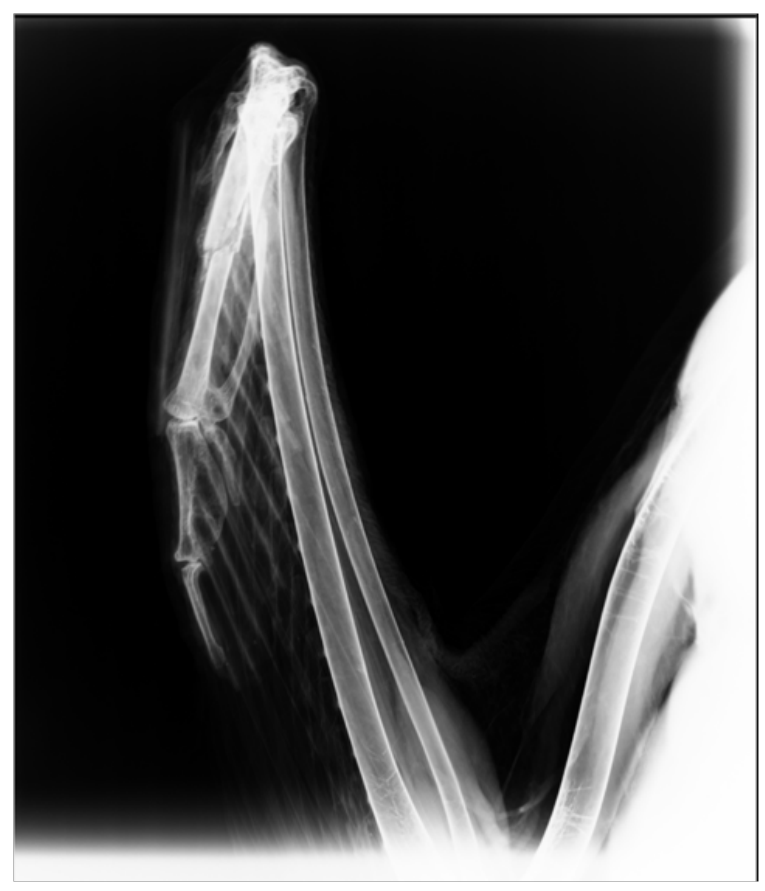

Figure I Radiograph image showing carpometacarpus fracture. 


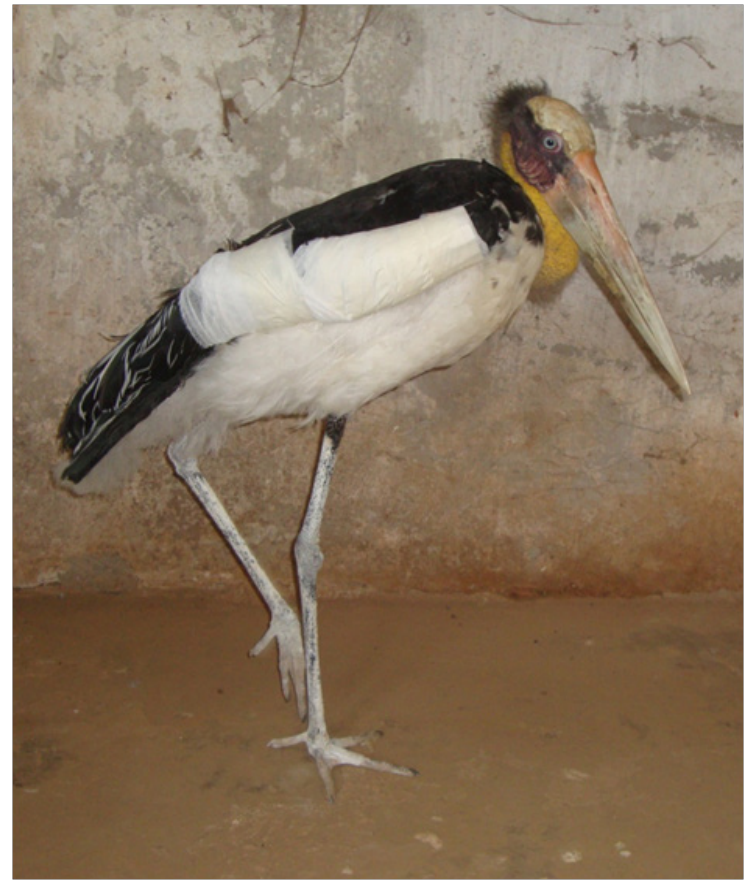

Figure 2 Wing wrap (figure eight bandage) to immobilize wing.

Postoperatively the bird was shifted to a small cell with proper ventilation to restrict its movement. Administration of broad spectrum antibiotics Fortivir injection @, 50mg (Virbac Animal Health India Pvt Ltd, Mumbai, India) intramuscularly daily for three days, analgesic Melonex injection@2.5mg (Intas Pharmaceuticals, Ahmedabad, Gujrat, India) intramuscularly daily for three days along with dressing of the wound in three days interval was carried out. Oral supplementation of calcium Orcal-P granules @ 5gms (TTK Health care, Chennai, India) once daily in feed and Vimeral liquid (Virbac Animal Health India Pvt Ltd, Mumbai, India) in drinking water was provided as supportive therapy. During the treatment period, the feed intake and activity of bird were observed improving.

On $15^{\text {th }}$ day postoperative, radiography was conducted, which revealed considerable callus formation at the fracture site indicating clinical signs of the union (Figure 3). The wing wrap along with splint was removed on the $15^{\text {th }}$ day and the bird was kept under observation in the same cell for another two weeks to restrict its movement. Gradually, the bird was seen flapping its wing and became active (Figure 4). After one month, the bird was removed from the small cell and released back to its enclosure. Normal wing movement and flight was observed inside the enclosure.

\section{Discussion}

Avian bones have a higher mineral content, resulting in an increased incidence of open, comminuted fractures with multiple sharp fragments that can traumatize soft tissue..$^{1-3}$ The decision about the method to repair the fracture depends on several factors, including the bird's future ability and function. ${ }^{4}$ The treatment and outcome may be different for a captive bird that does not need to fly or capture food, as compare to wild bird that requires flight and hunting to capture food and thrive successfully in the wild..$^{5}$

In this case, the considerable callus formation occurred in 15 days. Clinically avian bones heal faster than mammalian bones and maximum callus formation is achieved in two to three weeks. ${ }^{1}$ Prolonged immobilization may result in ankylosis of the involving joints, contraction of soft tissues and muscle atrophy. ${ }^{6,7}$ In this case, the bandage was removed in 15 days and wings were set free to prevent ankylosis. It has been reported that treatment such as intramedullary pins, bone plate fixation or external skeleton fixation require prolonged hospitalization of avian patients.

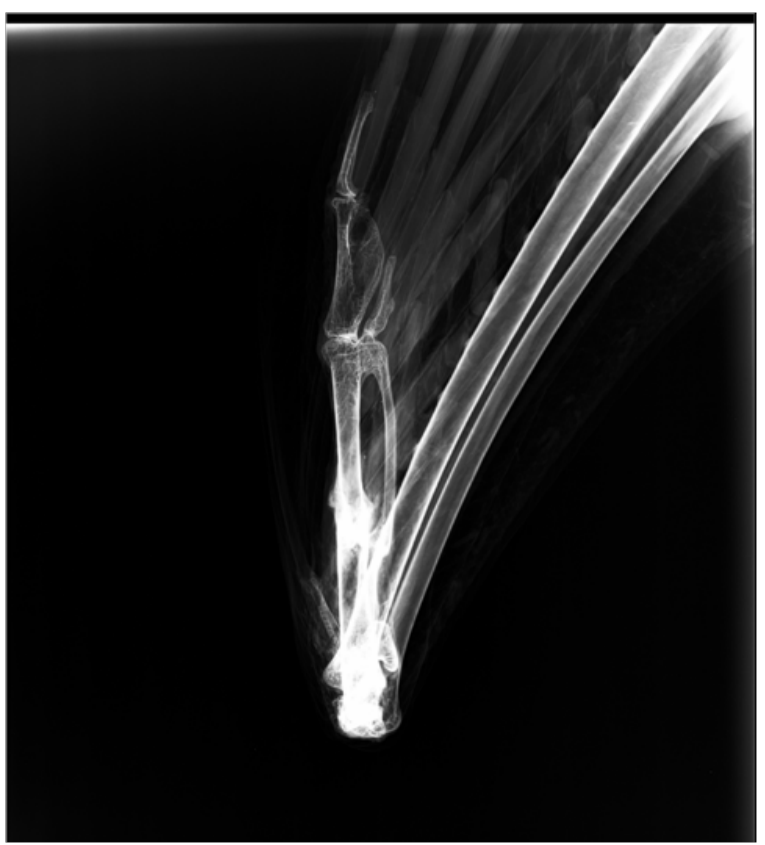

Figure 3 Adequate callus formation at the fracture site (I5 days post operative).



Figure 4 Bird showing normal use of the wing (30 days post operative).

External coaptation is an inexpensive and rapid method of providing increased comfort to an avian patient (decreased movement of bone ends) and minimal stabilization of a fracture. ${ }^{4}$ It is preferred over other methods of treatment as it provides fracture reduction with little or no trauma to the vascularity of bones and surrounding soft tissue. $^{3}$

After considering the above facts, the treatment of choice for the lesser adjutant stork was external coaptation. Bandages and splints should be made with light-weight material with the minimal amount of padding needed to compensate for swelling of damaged soft tissue. ${ }^{8}$ 
In this case, the bird was treated after careful physical restraint. Splints can often be applied using physical restraint if the bone doesn't need to be manipulated extensively although general anaesthesia will allow for the greater muscle relaxation and will prevent pain sensation. ${ }^{4}$ Fractures of the carpometacarpus can be easily applied with a figure ' 8 ' bandage to stabilize the fracture. ${ }^{8}$

\section{Conclusion}

This communication reports the successful management of right carpo-metacrpus fracture with the light-weight bamboo splint as external coaptation technique. The bird was successfully treated and released back to its enclosure after one month.

\section{Acknowledgements}

The authors are thankful to the Nandankanan Zoological Park authority for permission and support to carry out the work.

\section{Conflict of interest}

Author declares that there is no conflict of interest.

\section{References}

1. Jones R. Fracture Management in Birds. Vet Times. 2013.

2. Dar KH, Dar MUD, Adil S, et al. Surgical management of compound metacarpal fracture in Black Kite (Milvus migrans): A Case Report. Inter $J$ Vet Sci. 2015;4(2):101-103.

3. Bush M, Montali RJ, Novak GR. The healing of avian fractures: A histologic xeroradiographic study. J Am Anim Hosp Assoc. 1976;12:768773 .

4. Sahu SK, Nath I, Singh J, et al. External Coaptation for management of carpometacarpus fracture in a grey pelican (Pelecanus philippensis). Indian Wildlife Yearbook. 2013;11(12):140-143.

5. Forbes NA. Avian Orthopaedics. Vet Quarterly. 1998;20:S69-S70.

6. Kuzma AB. Avian Orthopaedics: An update and review of new techniques. Proc Annu Meet Am Assoc Zoo Vet. 1990;159-162.

7. Benett RA, Kuzma AB. Fracture Management in birds. Journal of Zoo and Wildlife Medicine.1992;23(1):5-38.

8. Ritchie BW, Harrison GJ, Harrison LR. Avian Medicine: Principles and Application. Florida: Wingers Publishing; 1997. p: 1145-1153. 